Proceedings

\title{
Introducing Novel Bidirectional Telemetry Technologies in Advanced Pressure Management; The Case of Athens, EYDAP SA, Greece ${ }^{+}$
}

\author{
Eirini Bougoulia ${ }^{1, *}$, Dimitris Foufeas ${ }^{2}$ and Nicholas Petroulias ${ }^{3}$ \\ 1 Melcer Consulting, Skyrou 2b, Agia Paraskevi, PC 15342 Athens, Greece \\ 2 OLYMPIOS TRADING SA, Skyrou 2b, Agia Paraskevi, PC 15342 Athens, Greece; df@olympios.gr \\ 3 Melcer Consulting, Skyrou 2b, Agia Paraskevi, PC 15342 Athens, Greece; np@melcer.gr \\ * Correspondence: irenempougoulia@hotmail.com; Tel.: +30-697-922-3378 \\ + Presented at the 3rd EWaS International Conference on "Insights on the Water-Energy-Food Nexus", \\ Lefkada Island, Greece, 27-30 June 2018.
}

Published: 31 July 2018

\begin{abstract}
New bidirectional technologies for remote access and control of DMAs are introduced into the Advanced Pressure Management field. Using interconnected devices, a controller at the PRV and a logger at the DMA's Critical Point, it is attempted to reach the optimal performance of the network in terms of pressure, energy consumption, economic parameters, losses and broken pipe events frequency. All manual adjustments are implemented remotely through an integral 2-way web communication system, allowing accessibility from any place, at any time. A case study of a 2year trial period in Athens, Greece is presented.
\end{abstract}

Keywords: advanced pressure management; DMA; remote control; critical point; urban water distribution management

\section{Introduction}

The application of Pressure Management throughout water distribution systems has over decades, proven to be one of the most efficient intervention methods when it comes to both reducing the physical water losses, as well as protecting the network's infrastructure health [1]. In its advanced form, pressure management takes advantage of key factors in a DMA, such as flow or time and seasonal consumption patterns, to better serve the needs of the zone in the process of eliminating excess pressure in the maximum possible degree [2], thus affecting all the losses parameters that are connected to overpressure conditions.

Taking advanced pressure management one step further, the latest applied solutions try to take into account the minimum pressure needs at the critical point or points, thus integrating these values into the multi-parametrical behavior of the pressure control system. The goal of the case study was to implement and perfectionate an empirical critical point-based flow modulation pressure management system, combining these two advanced pressure control methods to create a more evolved one, which will compensate for the flaws related to solely flow-based control systems. The two primary deficiencies of flow modulation technologies are in case of a burst that (a) the controller opens the valve up in order to satisfy the leak rate, as the leak is perceived as a higher demand in the zone, resulting in greater leakage losses and (b) there is a solid risk of causing transients and thus, new bursts, once the existing leakage repair is completed, if the PRV hasn't been appropriately adjusted manually on site.

At the same time and primarily, we aimed at the best possible ratio of bursts/insufficient pressure. This factor was defined as the expression of optimal pressure fluctuation throughout the 
zone, over a long time period, appropriate for every season, day of week and time of day considering that excess pressure is vitally linked to the appearance of bursts.

In our case study in order to achieve these two aforementioned goals, it was selected to apply the Pegasus+ pressure control system, developed by HWM-Water Ltd. (Cwmbran, UK), which additionally integrates a 2-way GPRS communication system. This feature provides for the possibility to not only collect and assess the real-time data from any place at any time, but also allows for the remote control of the system. After two years since the project's implementation, the objectives have been reached on a fully satisfactory level. The network runs at a high performance level, whilst minimizing the administrative response time and the field works hours. The study reflects the fine balance between the use of smart technologies and the human judgement factor in the Pressure Management field, as through the combination of these two, one is constantly learning from the other.

\section{Case Study, Materials and Methods}

A DMA was selected by the Water and Sewerage Utility of Athens, Greece (EYDAP SA) to be used for the pilot application of the proposed pressure control solution for a trial period, implemented by the Greek company OLYMPIOS TRADING SA. The "Tempon" DMA is a +190 above sea level (ASL) PRV zone which qualifies as a small one, a desirable feature which has proven to produce more secure and reliable results; 2719 supply connection points, $8518 \mathrm{~m}$ of pipeline, covering an area of $606,000 \mathrm{~m}^{2}$, maximum building height at 6 storeys and an extremely unique morphology of a long-narrow shape with an area of dynamic ground relief $(60 \mathrm{~m}$ difference within the zone's width) right after the inlet point (Figure 1). This particular DMA was proposed based on the fact that it presented with one of the highest dissatisfaction rates on behalf of the Utility's end users. The frequency of officially recorded complaints by citizens, due to low levels of pressure, was running extremely high forcing the Department in charge to constantly adjust the PRV's operation, manually on site, to cover the end point supply demands. The combination of the aforementioned features made Tempon eligible for the pilot implementation.

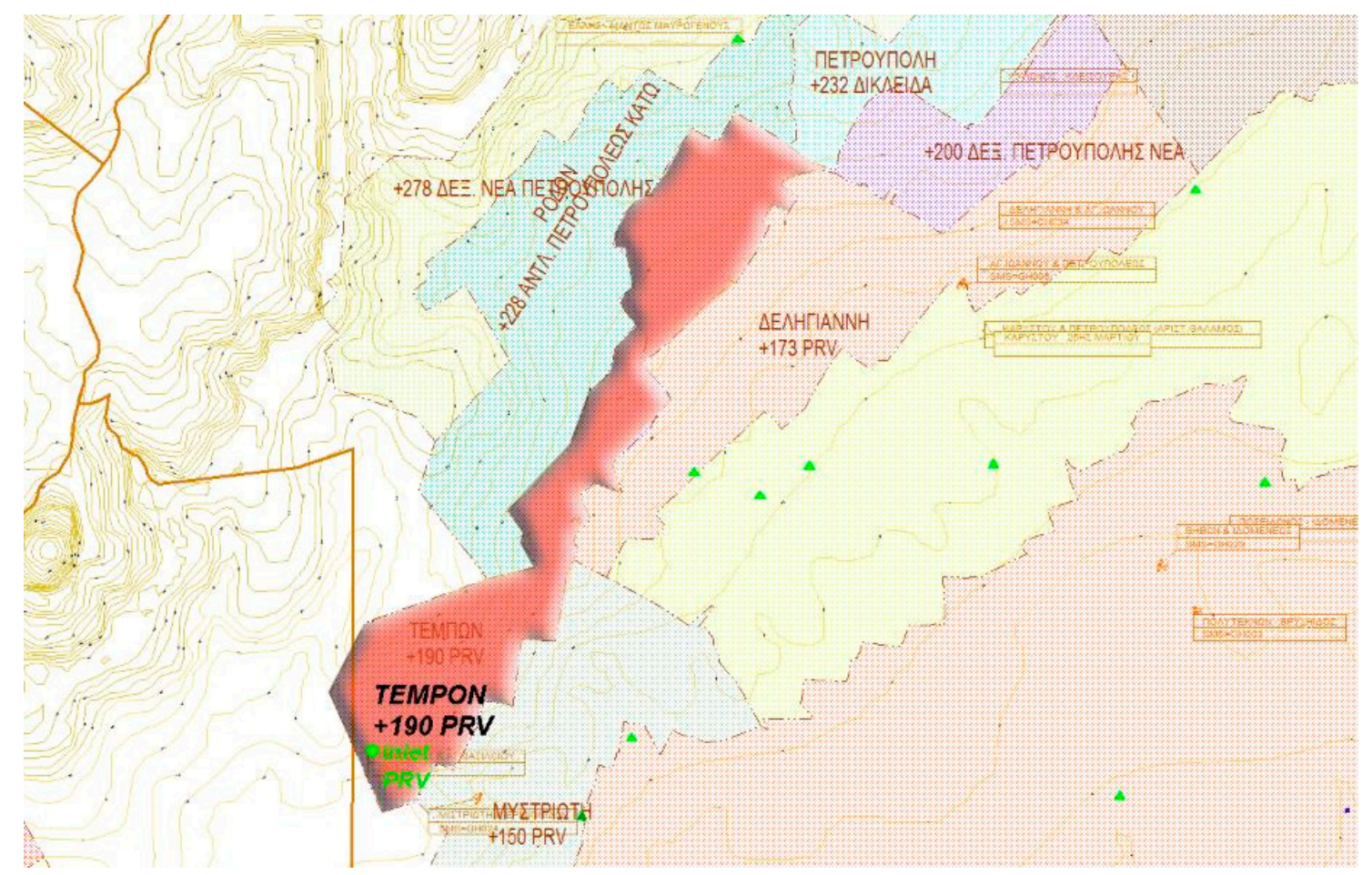

Figure 1. The selected Tempon +190 PRV DMA.

In July 2016, the Pegasus+ system was set to control the DMA. A controller was installed at the PRV point, regulating the valve's pilot and programmed on site through the programming app via a PC (Figure 2). The corresponding system's web viewer allows for easy and convenient access to data 
via the internet, providing all the necessary logging info, alarms, diagrams, measurements etc. The software also provides full automatic closed loop operation (used only for flow and time based function modes), including one or multiple Critical Point's auto-learning functions and auto-updates. A telemetry logger was set up and programmed at the DMA's $\mathrm{CP}$, providing frequent data to the system (Figure 3).

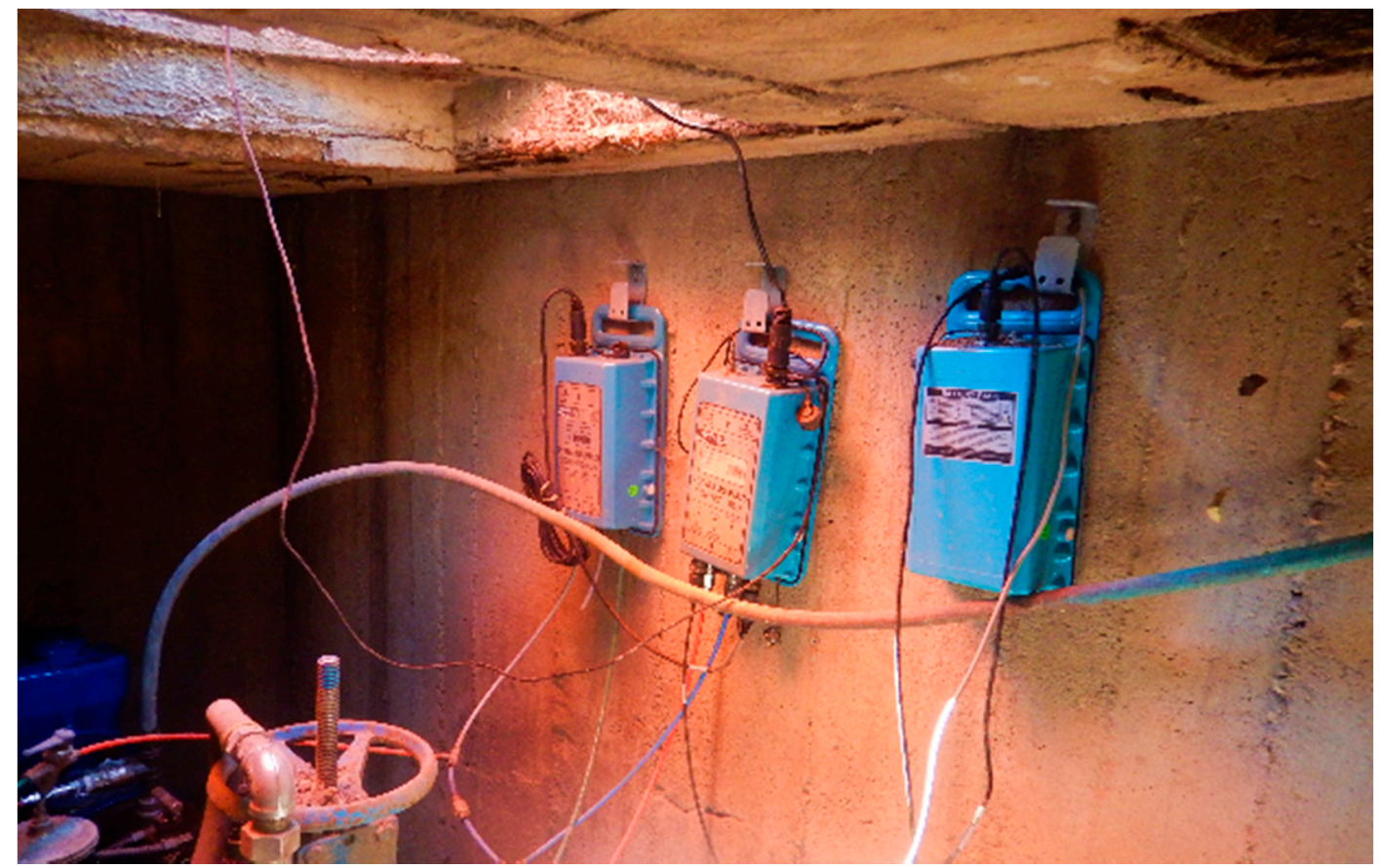

Figure 2. The Pegasus+ controller at the PRV installation site.

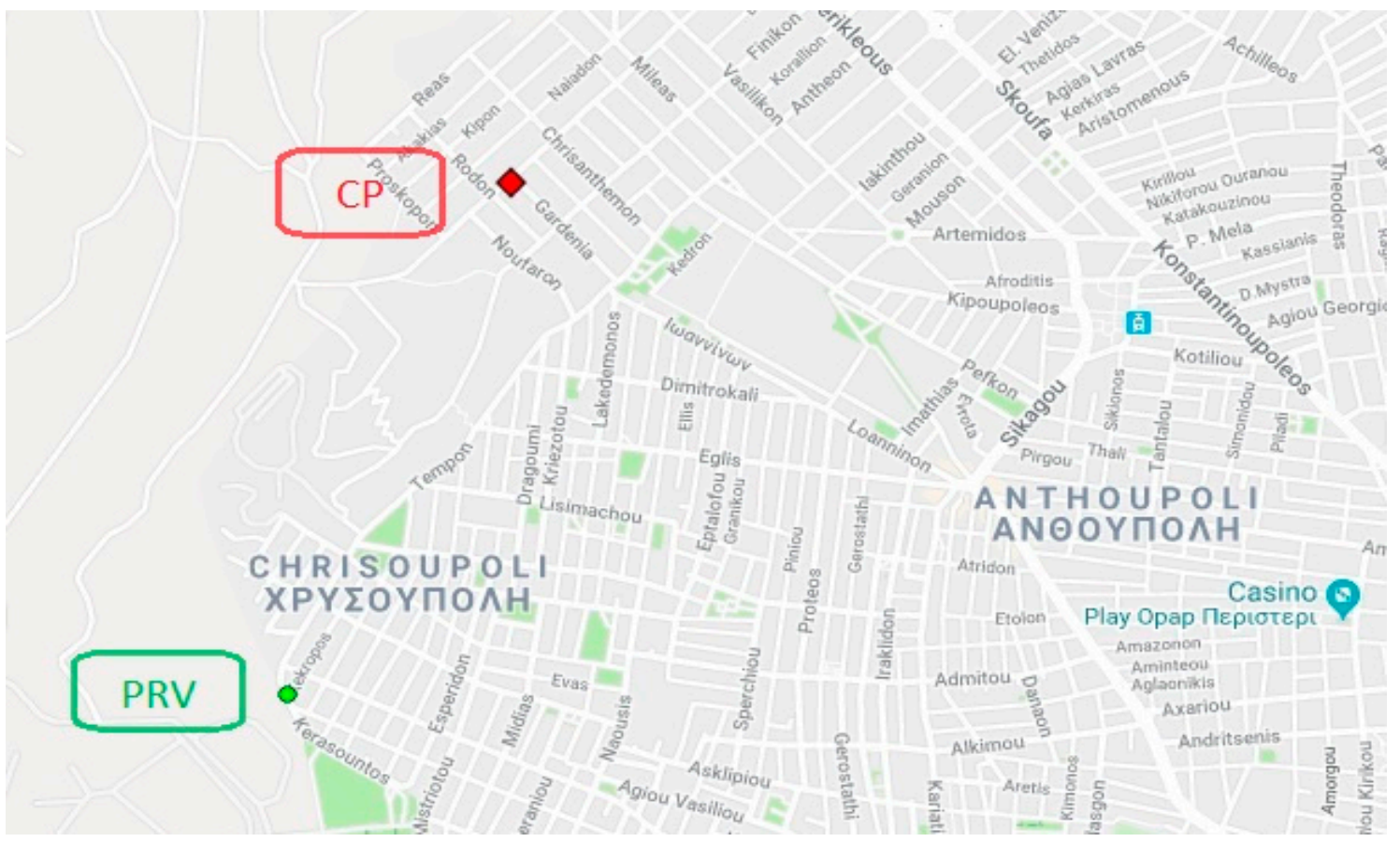

Figure 3. Map of the PRV site and Critical Point CP.

After the installation and programming of the controller and the logger, the zone's behavior was assessed on a daily basis and regulated when needed, with a collaboration of all three parties involved: the Utility's Department as the manager, the OLYMPIOS technical department as the implementer and HWM-Water Ltd. as the manufacturer/developer. We ran through an 18-month 
learning period, during which the minimum pressure at the Critical Point was set as a target for the system's operational mode, constantly adjusting this value to observe the reaction of the DMA's performance in matters of consumption, bursts, losses and pressure efficiency. During this learning period, the software collected data to produce patterns and value pairs for flow and outlet pressure at the PRV, based on constantly auto-regulated algorithms. The learning phase of the trial was set to end in the first months of 2018.

\section{Results}

The web software that controls the system, offers some possibilities that automatically resolve the known problems of flow modulation pressure management. The user can set limits regarding the outlet pressure, meaning that in case of a burst, the flow rate at the leakage will not exceed a maximum value, minimizing the unavoidable losses that will naturally incur during the leakage runtime. Moreover, the feature of event alarms ensures that the user will be notified of this significant change in demand, which therefore serves as a notification of possible existing burst in the DMA, even if it has not yet been visually observed. Thanks to the remote access to the controller, the valve can be appropriately adjusted at the time of the repair works, to avoid transients and new bursts in the network. The user-friendly platform also provides for the exceptional opportunity to study the DMA's behavior because it includes analytical data and logging info, referencing each change and adjustment that was applied, naming the user that forced each modification in a complete operational history file.

The pressure control system in the DMA, has now been running adjustment-free on flow modulation for 3 months, based on the produced patterns and paired values that were developed from the auto-learning period, with a combined CP preset lower pressure limit of $27 \mathrm{~m}$ (closed loop operation). During this current three-month operational state of $\mathrm{CP}$ based flow modulation, the DMA has reached a perfect bursts/insufficient pressure level of $0 / 0$, meaning that there have been zero broken pipe events and zero complaints on behalf of the end users, regarding inadequate pressure (Figure 4). Additionally, on field man-hours have been significantly reduced, as the response time has been practically minimized thanks to the remote control feature provided by the system's software (“PressView" Version 1.41.6015.20292, 20 June 2016).

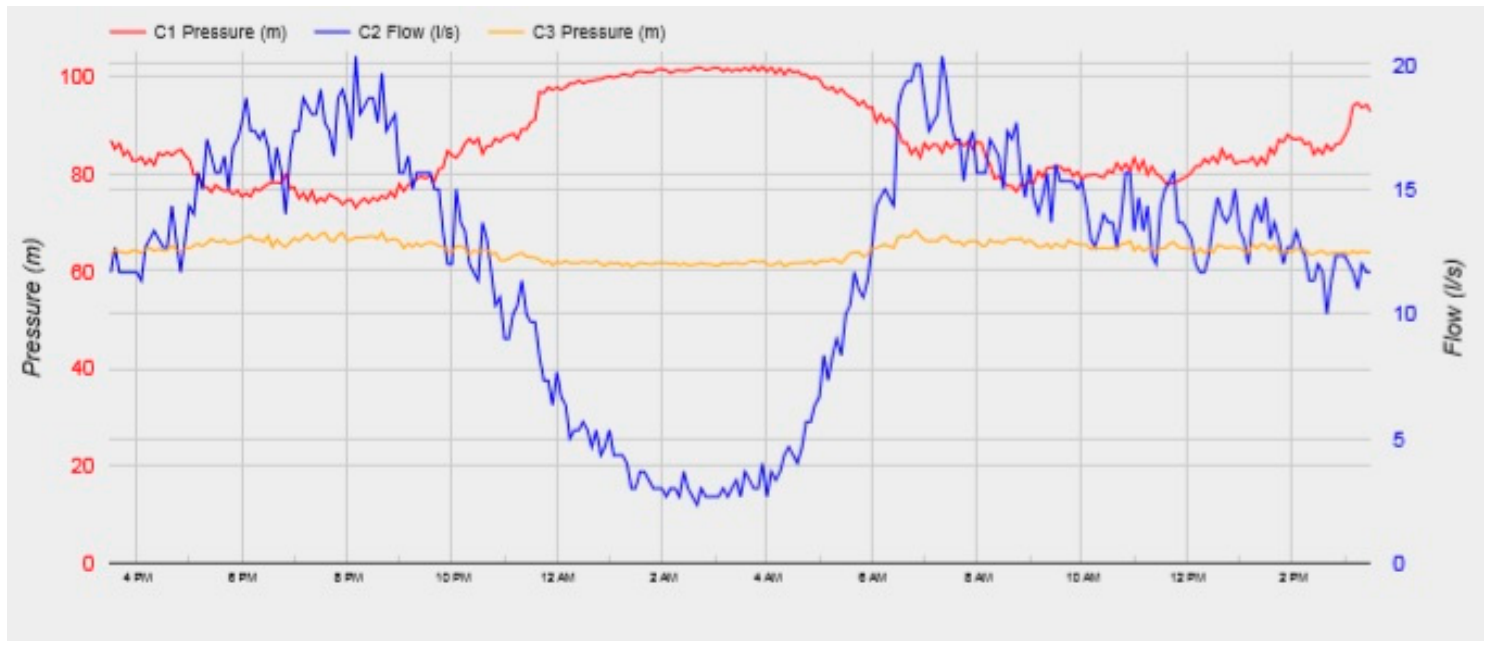

Figure 4. 24-h (15 min) diagram at the DMA's PRV site from the 5th to the 6th of June 2018.

Three indicative groups from different weeks of the DMA's key measurements are presented below to reflect the learning process of the system (Figures 5-7). Each group includes the weekly DMA pressure-flow diagram, the corresponding data table and the CP pressure diagram with its statistics. The first one is about 2 months after the implementation, so it's at a beginner's stage. The second one is almost one year after the implementation. The third one which is exactly one year after that, is the current state (June 2018). Since the second one and third one are the exact same week of 
two consecutive years (eliminating thus the seasonal parameter of the consumption patterns) and given that a one-year period is practically not enough for any significant demographic changes, it is safe to assume this is a reliable pattern comparison pair [3] (p. 2). The three different groups present with (a) a rise in the stabilization of the critical point pressure, as its range and fluctuations appear to smoothen out and (b) a fairer allocation of the flow curve throughout the day, matching the onset goal of the study to better serve the needs of consumption and minimize the customers' complaints, meaning that the system steadily learned and adjusted onwards to meet the DMA demands, doing so slowly to avoid bursts in the network.

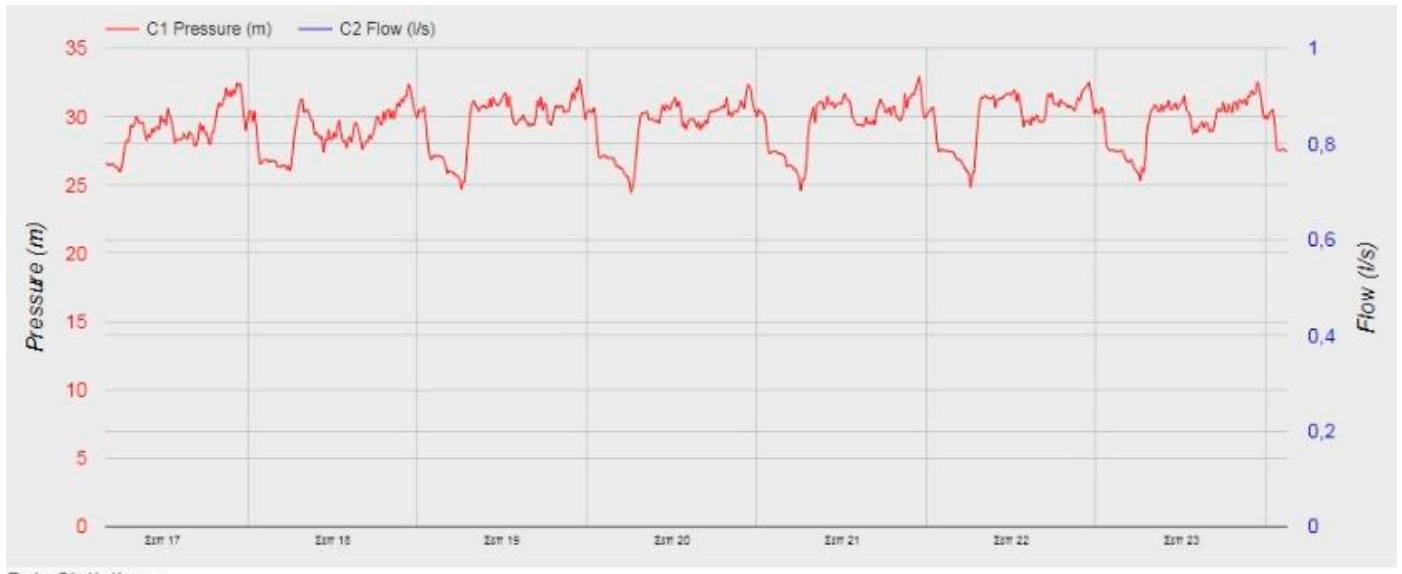

Data Statistics

\begin{tabular}{llll}
\hline Channel & Max. & Min. & Average \\
\hline C1 Pressure $(m)$ & 32.933 & 24.433 & 29.436
\end{tabular}

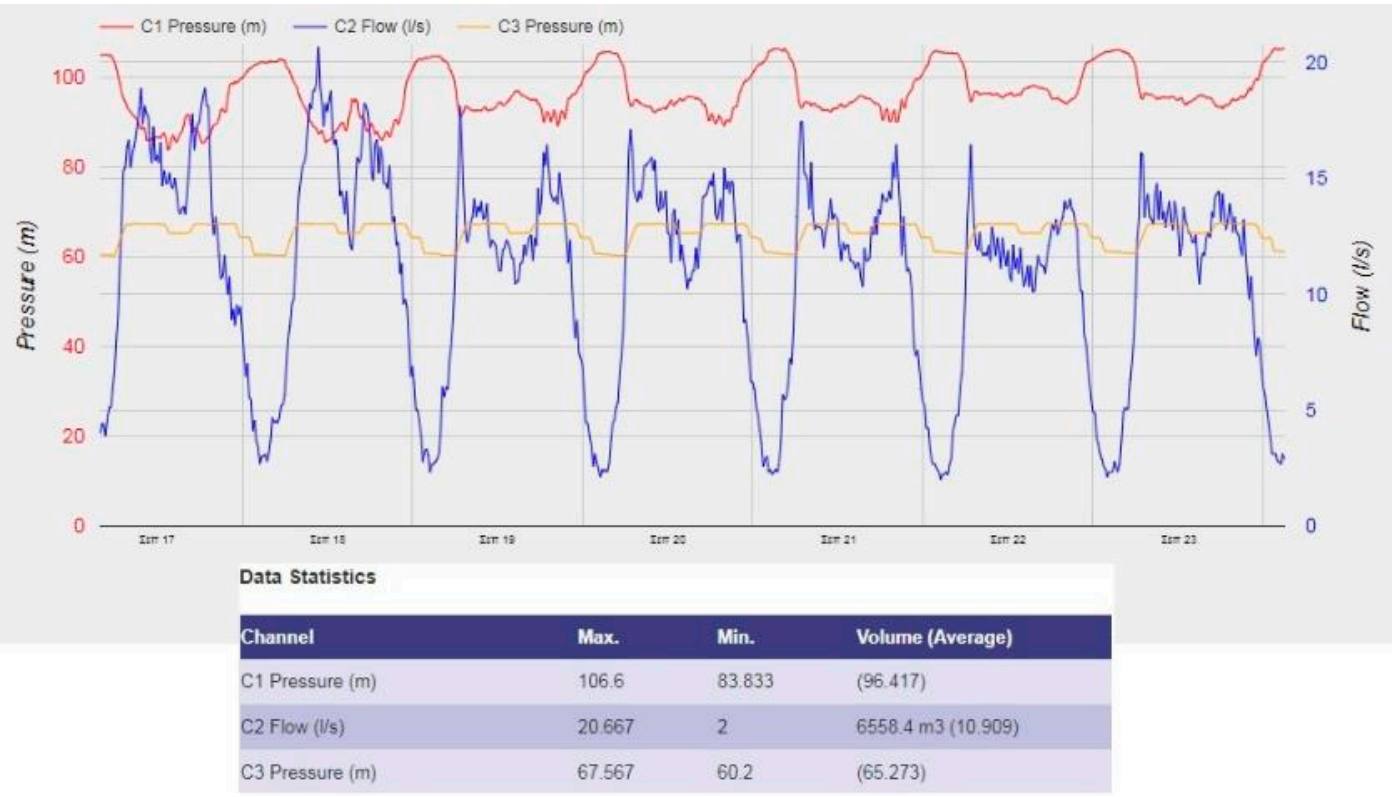

Figure 5. Weekly set of data from the 17th to the 24th of September 2016. 

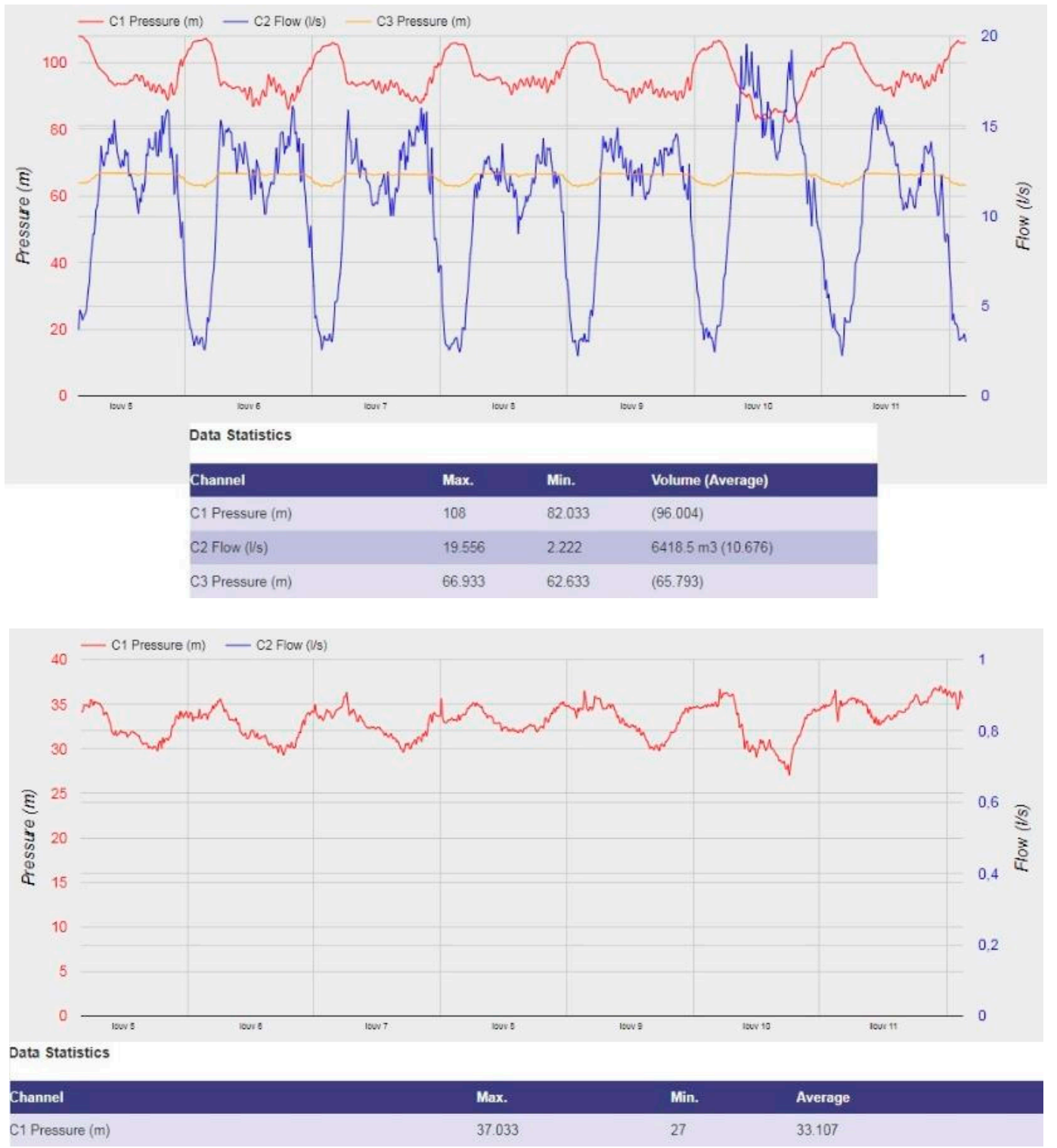

Figure 6. Weekly set of data from the 5th to the 12th of June 2017.

When it comes to the flow data provided by the figures, the first set will not be taken into account, as it represents a diametrically opposite season from the second and third one. For example, between September 2016 (Figure 5) and June 2017 (Figure 6) there is a small rise in the minimum night flow but a small decrease in the average flow and volume, which could be related to leakage losses in the network, but it could also be a change in the consumers' pattern, since it is possible that in June people tend to go on out of town trips (thus, the decrease in average volume) but also tend to stay up late, or at least later than in September.

Comparing the data between the second (Figure 6) and third (Figure 7) group, there is a rise in maximum flow, minimum flow, average flow and volume between June 2017 and June 2018. At the same time, there is a decrease in the average zone pressure and an amplification of the pressure range (max. to min.) which implicates that the zone is now able to satisfy the consumer needs more efficiently than before, operating at a lower average pressure which is more fairly dispersed throughout the day. 

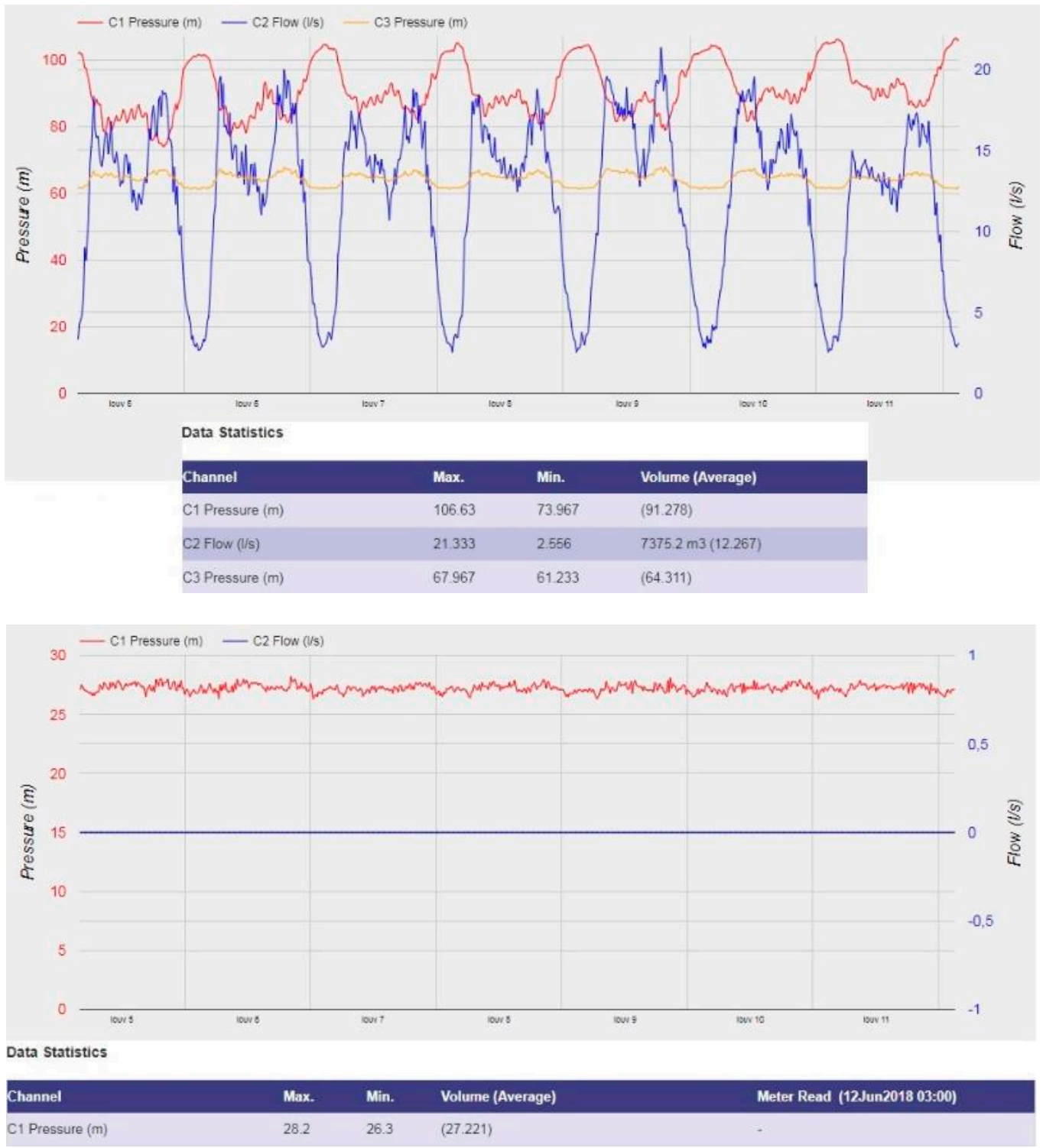

Figure 7. Weekly set of data from the 5th to the 12th of June 2018.

The minimum flow has risen by $13 \%$, while the average volume rose by $15 \%$. This increase in the minimum night flow is not considered surprising, as it is in accordance with the primary hypothesis of the study; the goal was to reach the balance in pressure management, and not it lowest degree, as in that case there are the issues of insufficient pressure. During this trial period, bursts were effectively dealt with, but there was no other loss reduction method implemented, such as Active Leakage Control, with the purpose of receiving data and conclusions related only to the applied pressure management method. Given that the two patterns of Figures 6 and 7, refer to the same week of two consecutive years, it is safe to assume that there was no significant rise in the night consumption to justify that rise. Thus, the increase derives from leakages (background or unreported ones) reflecting the rise of flow at existing leak points or appearance of new ones, due to the rate of rise of leakage in every network without ALC (Figures 8 and 9) [4]. Even so, this rise is economically counterbalanced by the rise in flow throughout the day that is clearly not only or respectively linked to the leakage flow. In this case, the ratio of MNF to average flow is 1 to 5 . 


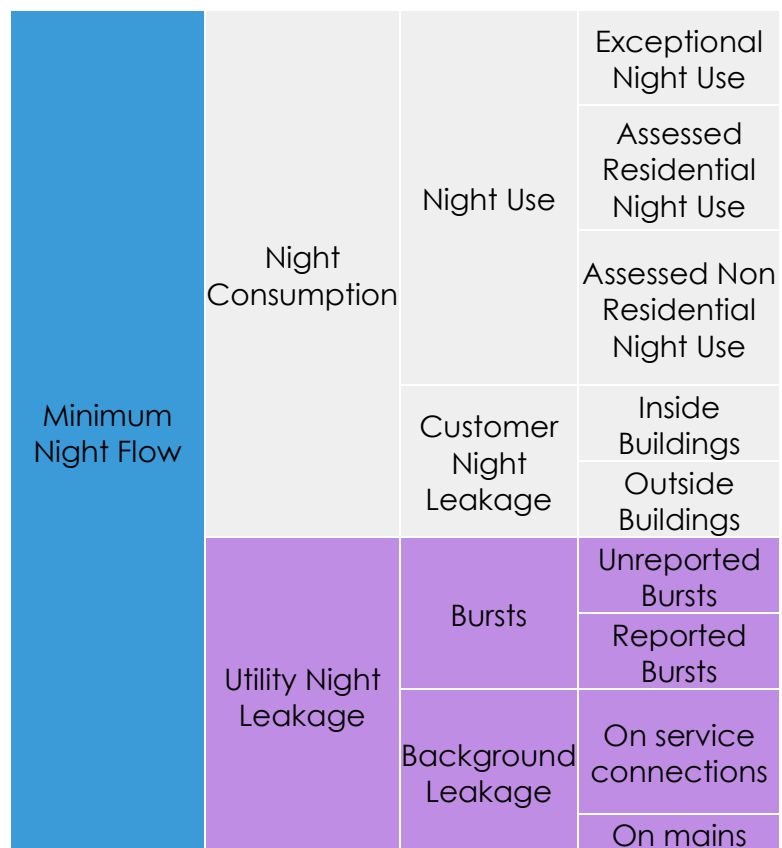

Figure 8. Components of Minimum Night Flow, source: WLSG Night Flow Team (2010) [4].

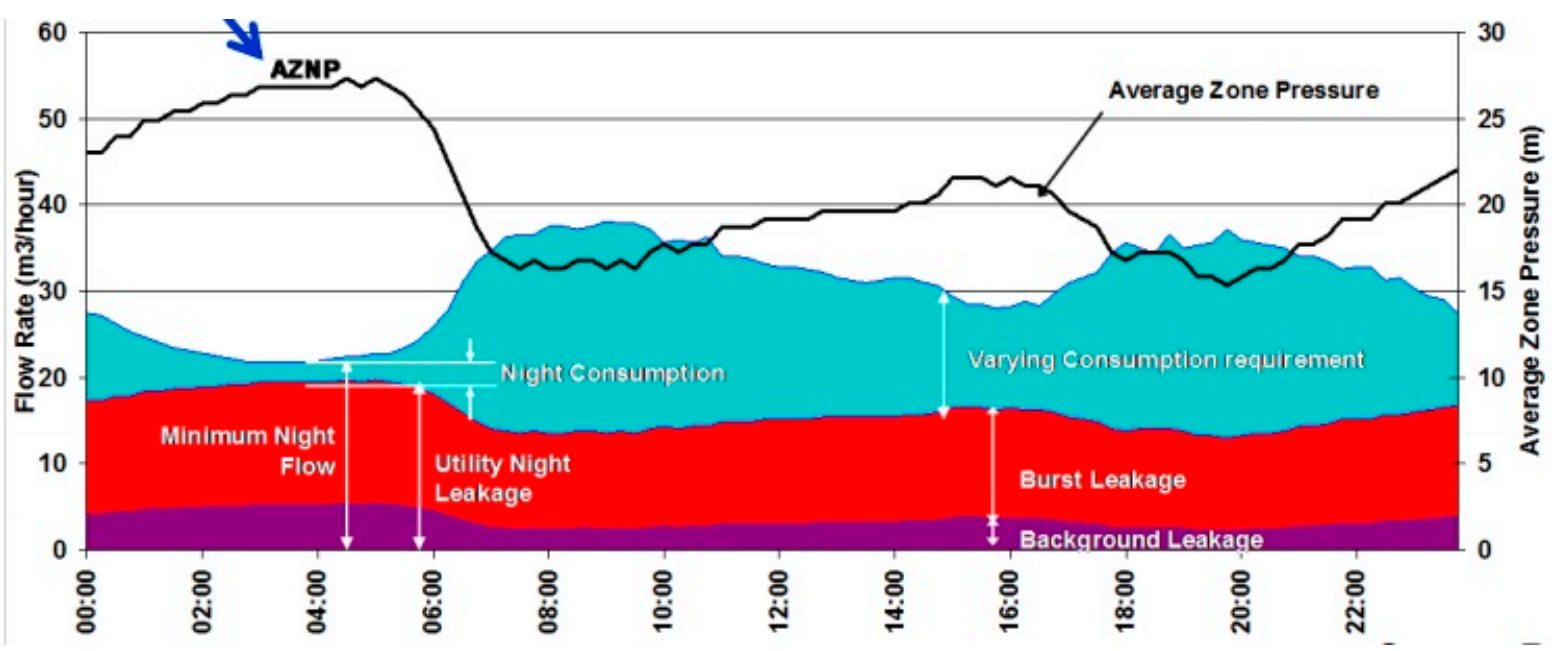

Figure 9. Variation of Utility Leakage Components with AZP, source: R.Liemberger [5].

\section{Conclusions}

To achieve permanent results, management procedures related to a utility's organization and human resources have to be changed [6]. Additionally, the implementation of an intelligent Pressure management system is an efficient approach to reduce the total real losses in the long term. It is one of the most basic and lucrative forms of optimizing a system and it generally provides fast investment paybacks [7].

The triple combination of advanced pressure management, smart remote control technologies and human judgement factor has in our case produced a fairly efficient water distribution system of optimal performance indicator numbers. The objective of client satisfaction as seen through the prism of sustainable development for the provider's part, has been fully achieved. The goals that were set at the beginning of the case study have been met, as the zone is operating more efficiently, presenting no bursts and no inadequate pressure events, so far. A new objective has been now defined; we will test the use of an energy producing device to supply power to the installed pressure control system at the PRV, in order to create a model autonomous control system that is fully sustainable and selfsufficient. 
Author Contributions: D.F., N.P. and E.B. conceived and designed the experiments; D.F. performed the trial; N.P. and E.B. analyzed the data; E.B. wrote the paper.

Acknowledgments: Water and Sewerage Utility of Athens (Greece) EYDAP SA for permission to reproduce the data shown in Figures 1-7, K. Lyberis of the Operational Dept. of EYDAP SA's Water Network Directory for providing info regarding the DMA, HWM-Water Ltd. (UK) for providing the technological material, E. Balokas as Technical Manager of OLYMPIOS and Project Manager for contributing to the technical know-how.

Conflicts of Interest: The authors declare no conflict of interest.

\section{References}

1. Farley, M.; Trow, S. Losses in Water Distribution Networks: A Practitioner's Guide to Assessment, Monitoring and Control, reprint ed.; IWA Publishing: London, UK, 2003; pp. 145-182.

2. Wright, R.; Parpas, P.; Stoianov, I. Experimental Investigation of Resilience and Pressure Management in Water Distribution Networks. Procedia Eng. 2015, 119, 643-652, doi:10.1016/j.proeng.2015.08.917.

3. Studio Marco Fantozzi. Available online: http://www.studiomarcofantozzi.it/ (accessed on 30 May 2018).

4. Water Leakage and Pressure Management. Available online: http://www.leakssuite. com/ (accessed on 30 May 2018).

5. Fantozzi, M.; Lambert, A. Legitimate Night Use component of Minimum Night Flows Initiative: Report by Marco Fantozzi. In Proceedings of the Water Loss 2010, São Paulo, Brazil, 6-9 June 2010.

6. Farley, M.; Liemberger, R. Developing a non-revenue water reduction strategy: Planning and implementing the strategy. Water Sci. Technol. Water Supply 2005, 5, 41-50, doi:10.2166/ws.2005.0006.

7. Thornton, J.; Sturm, R.; Kunkel, G. Water Loss Control, 2nd ed.; McGraw-Hill Education: Columbus, $\mathrm{OH}$, USA, 2008; pp. 301-343.

(C) 2018 by the authors. Licensee MDPI, Basel, Switzerland. This article is an open access article distributed under the terms and conditions of the Creative Commons Attribution (CC BY) license (http://creativecommons.org/licenses/by/4.0/). 